\title{
An Experimental Investigation into the Effect of Soap on Ignition and Combustion Characteristics of Single Droplets of Glycerol
}

\author{
Hendrix Y Setyawan, Mingming Zhu*, Zhezi Zhang and Dongke Zhang \\ Centre for Energy (M473), The University of Western Australia, 35 Stirling Highway, \\ Crawley, WA 6009, Australia
}

(A manuscript offered to "Combustion Science and Technology")

* Corresponding author:

Dr. Mingming Zhu

Email: mingming.zhu@uwa.edu.au

Phone: +61864887600

Fax: $\quad+61864887622$ 


\begin{abstract}
The ignition and combustion characteristics of single droplets of glycerol with soap addition were studied experimentally. Soap was added into a pure glycerol at concentrations of 1 to $5 \mathrm{wt} \%$. A single droplet was suspended on the tip of a silicon carbide fibre and exposed to air at $1023 \mathrm{~K}$. The ignition delay time, burnout time and burning rate were determined. A flame emission spectrometer was used to identify the presence of sodium in the flame. Results showed that combustion of the glycerol droplets with soap addition occurred in a two-staged manner: (1) the first stage where glycerol preferentially was evaporated and burned and (2) the second stage where soap was evaporated and burned. The soap addition in the glycerol reduced the ignition delay time, shortened burnout time and improved burning rate of the droplets. Sodium ions detected to present in the flame promoted the combustion rate of the fuel vapour.
\end{abstract}

Keywords: Droplet, Glycerol, Ignition, Soap, Sodium 


\section{Introduction}

Crude glycerol is an inevitable by-product of biodiesel production, which contains free glycerol and impurities (water, methanol, soap, etc.). In 2014, production of crude glycerol was approximately 2.8 million metric tonnes (MMT), higher than the global market could absorb at approximately 2 MMT (Ciriminna et al., 2014). In order to utilise the glycerol, a number of technologies have been proposed and evaluated (Papanikolaou et al., 2008; Wongwuttanasatian \& Sakkampang, 2016). However, the costs of these technologies are expensive and the values of the products generated are too low.

Combustion of crude glycerol has been identified as the simplest glycerol utilisation method (Quispe et al., 2013), particularly for combined heat and power generation in a biodiesel production plant which would eliminate the costs of transportation and fossil fuel dependency (Da Silva et al., 2009). Direct combustion of glycerol (pure and crude glycerol) in a burner (Bohon et al., 2011) (Steinmetz, et al., 2013) or in a modified CI engine (McNeil et al., 2012) has been attempted. Combustion of a mixture of crude glycerol with other fuels was also experimentally studied, such as a mix of glycerol with propanol (Dee \& Shaw, 2004), yellow grease (Patzer et al., 2007), biomass (Raslavičius, 2012) and heavy oil (Striugas et al., 2008), respectively.

One of the challenges associated with the combustion of crude glycerol is the impurities present in the crude glycerol (Coronado et al., 2014). Such impurities include methanol, water, soap, fatty acid methyl ester (FAME), glycerides, free fatty acid (FFA), as well as ash (Hu et al., 2012; Da Silva \& Mota, 2011), all of which could potentially influence the ignition and combustion of glycerol. Understanding of the effect of each of those impurities on the ignition and combustion of glycerol is essential in utilising crude glycerol as a fuel but such information is scarce in the literature. Our previous work studied the effect of water (Setyawan, et al., 2015) and methanol (Setyawan, et al., 2013) on the ignition and combustion characteristics of pure glycerol droplets. Extending our previous studies, the present experimental work examined the effect of soap on the ignition and combustion characteristics of glycerol. 
Soap in crude glycerol is derived from sodium hydroxide $(\mathrm{NaOH})$, a base catalyst for biodiesel production. In a trans-esterification process for a biodiesel production, excess of $\mathrm{NaOH}$ reacts with free fatty acid from oil/fat in the presence of water, producing soap as an unwanted by-product. The content of soap in the crude glycerol can be up to $20 \mathrm{wt} \%$ (Hu et al., 2012).

The combustion of soap results in the ash formation due to the existence of sodium, causing corrosion problems (Cheong, 1998). However, the sodium contained in the soap may also promote ignition and combustion of glycerol since some sodium containing additives have been found to reduce ignition temperatures of hydrocarbon fuels (Graham, et al., 1976) and suppressing NOx emissions (Lissianski et al., 2001).

Against this backdrop, an experimental study of ignition and combustion behaviour of single droplets of glycerol, with and without soap addition, was performed. The results were expected to provide good understanding of effect of soap on the ignition and combustion of glycerol and better utilisation of crude glycerol as a fuel.

\section{Experimental}

\subsection{Materials}

Employed for the current study was a pure glycerol, purchased from Sigma Aldrich, and a soap. The physical properties of the glycerol are listed in Table 1. The soap was made by the following procedure. A $5.08 \mathrm{~g} \mathrm{NaOH}$ was dissolved in $15 \mathrm{~g}$ water and the mixture was then poured into a flask containing $8.5 \mathrm{~g}$ olive oil to allow the reaction occurs. The flask was heated to $60^{\circ} \mathrm{C}$ for 15 minutes. The general formula of the soap was $\left(\mathrm{NaCOOR}_{1}\right)$, with $\mathrm{R}_{1}$ being the fatty acid from the olive oil. The fatty acid compositions of the olive oil are listed in Table 2.

\subsection{Experimental Equipment and Facilities}

The soap was added into the pure glycerol at concentrations of $1 \%, 3 \%$ and $5 \%$ by weight. The corresponding sodium contents in the mixtures were $0.1,0.3$, and $0.5 \mathrm{wt} \%$, respectively. For 
convenience in subsequent discussion, the pure glycerol and the glycerol with soap additions were denoted as PG and PGSx, respectively, with $x$ indicating the weight percentage of soap in the glycerol. For instance, PGS1 means pure glycerol with 1 wt \% of soap addition.

Figure 1a illustrates the single droplet combustion experimental setup, which consisted of a droplet suspension system, a horizontal tube electric furnace with temperature control for providing a hot air environment, a step motor (equipped with backlight) for delivering the droplet into the furnace, and a charge-coupled device (CCD) camera (Basler PIA-210gc) which was controlled by a computer for image capturing (Zhu et al., 2013). In a typical experiment, the temperature of the furnace was set at $1023 \mathrm{~K}$, representing the typical combustion temperatures in diesel engines, one of the possible means of utilising glycerol. A droplet was produced using a $10 \mu \mathrm{L}$ micro pipette and deposited on the tip of silicon carbide fibre of $0.142 \mathrm{~mm}$ in diameter. The initial droplet diameter $\left(d_{o}\right)$ in the current study approximately was $1 \mathrm{~mm}$. Aided by the step motor, the droplet was delivered to the centre of the furnace at a velocity of $1 \mathrm{~ms}^{-1}$. The combustion processes was recorded using the CCD camera to capture the time-sequenced images of the droplet combustion history. A halogen lamp provided back light to assist in capturing the change of droplet size during combustion.

\subsection{Analysis and Characterisation}

The ignition and combustion characteristics of PG and PGSx droplets were determined by analysing the backlit images and the un-backlit images taken by the CCD camera. The images of backlit burning droplets allowed the calculation of the rate of change of the droplet size, while the images without backlit helped the identification of the combustion phenomenon and flame characteristics. Using the back-lighted images taken by the CCD camera at $200 \mathrm{fps}$, the ignition delay time ( $\left.\mathrm{t}_{\mathrm{i}}\right)$ was determined as the period from the moment as the droplet reached the centre of the furnace to the moment when the first visible flame was observed. The burnout time $\left(\mathrm{t}_{\mathrm{b}}\right)$ was defined as the period from ignition until the completion of combustion of the droplet. The total combustion time was then 
the sum of the ignition delay time and burnout time. The images were post-processed so that the evolution of the droplet size (d) during combustion could be determined as well. The postprocessing of the images employed a super-resolution reconstruction (Shah \& Zakhor, 1999) and canny edge detection methods (Canny, 1986), which allowed the edge of a burning droplet to be identified accurately. The actual shape of the suspended droplet was elliptical due to the influence of gravity and a stated droplet size referred to an equivalent value determined as the cubic root of the product of the droplet width squared and the droplet length (Zhu et al., 2012). The droplet size used in this study was $1.0 \pm 0.02 \mathrm{~mm}$. Due to the finite resolution of identification of the boundary that yielded an error of 1 pixel, the inherent uncertainty in calculating the droplet diameter was estimated to be around $2 \%$ for the droplet in the present study. Once the time history of the droplet size was known, the burning rate was determined based on the classical $\mathrm{d}^{2}$-law of droplet combustion (Law, 2006). From the $d^{2}-t$ plot, the burning rate constant was determined as $k=-d\left(d_{o}^{2}\right) / d t$

A flame emission spectrometer was applied to detect the presence of sodium ions in the flame, especially for droplets doped with soap. Figure $1 \mathrm{~b}$ shows a schematic of the system. The spectrometer (StellarNet, BLACK-Comet-XR) permitted the acquisition of spectra in the wavelength range from 400 to $750 \mathrm{~nm}$ with a resolution of $1.5 \mathrm{~nm}$. The spectral energy was transmitted to the monochromators through a fibre optic cable, which was terminated with a collimator. This method can provide a simple and quick means of qualitatively determining the presence of sodium ions in the flame. The sodium signals measured by the spectrometer was recorded using the "Spectra Wiz' Episodic Data Capture" per $10 \mu \mathrm{s}$, starting from the arrival of the droplet at the centre of the furnace until the completion of the droplet combustion.

\section{Results and Discussion}

\subsection{Ignition and Combustion Phenomena of Single Glycerol Droplets}


Figure 2 shows typical time sequenced un-backlit images of combustion of droplets of glycerol with and without soap addition. The bright colour refers to the flame. From the left to right hand side are the images of the droplets from the moment when the droplets arrived at the centre of the furnace until the completion of combustion. Seen from Fig. 2, upon arrival at the centre of the furnace, the glycerol droplets with and without soap addition were of the same size. Upon ignition, flames were formed, surrounding the droplets. The flame of the pure glycerol droplet was greenish, suggesting a clean combustion with very little amount of soot particles formed. The oxygen moiety in the glycerol may promote the combustion, resulting in no or little soot formation. At the end of the pure glycerol combustion, the fibre tip was clean, free of any soot or ash deposit.

However, the combustion of glycerol droplets with soap additions differed. For example, in the case of PGS1, the ignition and combustion phenomena were similar to that of pure glycerol to begin with but the flame was clearly visible in yellowish colour. The change of the flame colour was mainly due to the presence of sodium ions in the flame as discussed in Section 3.3. There was no residue attached to the fibre tip (Image 4) at the end of combustion. The combustion of PGS3 and PGS5 started with yellowish flames (Image 2), which lasted for a period (Images 2 and 3) and then became dim in intensity and small in size (Image 4). After a very short period, the flame was then redeveloped as bright and yellow flame (Images 5 and 6). At the end of the combustion, there was still a small amount of solid residue left on the fibre tip (Image 7). This was believed to be the ash formed from mainly un-vaporised sodium and other metals that became mineralised (Bohon et al., 2011).

These phenomena can be explained by the well-known evaporation mechanism of a binary mixture with sufficiently different volatilities (Botero, et al., 2012). The vapour pressures of glycerol and soap differed vastly (Cammenga et al., 1977; Ferguson et al., 1938). When the glycerol/soap mixture experienced heat, the more volatile component, glycerol in this case, was preferentially evaporated and burned. The less volatile soap component would concentrate in a boundary layer near the droplet surface. Since the droplet surface would seek to remain near the boiling 
temperature of the mixture at the surface and, as the surface mass fraction of the soap would increase, the temperature of the droplet surface would also increase. When the glycerol evaporation approached the end, there was a short period during which the droplet temperature would increase rapidly and the evaporation rate of glycerol was extremely low, leading to the flame contraction. The flame growth afterwards was characterised by subsequent evaporation of the soap. Therefore, it is believed that the combustion process of the glycerol droplets with soap additions was composed of two stages that is, preferential evaporation and combustion of glycerol first, followed by evaporation and combustion of soap.

Figure 3 illustrates the temporal variation of the square of the normalised droplet diameter $\left(d / d_{o}\right)^{2}$ for droplets of PG, PGS5 and Pure Soap (PS) at 1023K. The droplet size was monitored from the moment of the droplet reaching the centre of the furnace until the completion of combustion. It is evident that the droplet size remained almost constant for PG and PS droplets during the ignition delay period and then showed an approximately linear reduction after ignition, implying that the droplet combustion conformed to the $d^{2}$-law (Law, 2006).

However, for PGS5, the changes in the droplet size resembled these of bi-component mixtures with vastly different vapour pressures, as discussed in the previous section and described in (Steinmetz, et al., 2013). The first segment of these curves represents the first stage where the glycerol was preferentially evaporated and combusted while the second segment represents the second stage during which the soap was evaporated and burned. Due to the relatively low content of soap, the second stage only lasted very briefly.

\subsection{Effect of Soap on Ignition Delay Time and Burnout Time of Glycerol Droplets}

Figure 4 illustrates the effect of soap addition on the ignition delay time, burnout time and total combustion time of glycerol droplets. It is evident that the ignition delay time was slightly reduced with increasing soap concentration. This suggests that the soap addition would have changed the rates of glycerol evaporation and subsequent chemical reaction of the fuel vapours. It is speculated that sodium in the soap released into the gas phase promoted the combustion reaction rate of the 
glycerol vapour in air during the ignition delay period, shorting the ignition delay time (Makino \& Fukada, 2005). It is also evident that the burnout time and total combustion time decreased with increasing soap concentration, which could be attributed to the enhanced burning rate.

Figure 5 displays the effect of soap addition on the burning rates of glycerol droplets at $1023 \mathrm{~K}$. Since the droplets with soap additions exhibited two stages of combustion, the burning rates of both stages were calculated and are shown in Fig. 5. Figure 5a shows the burning rate of PG and the first stage of PGx. It can be seen that the addition of soap increased the burning rates of glycerol droplets. Figure $5 \mathrm{~b}$ shows the burning rates of PGx and PS in the second stage. The average burning rates of the residues of PGS3 and PGS5 were similar to that of pure soap, confirming that the combustion of PGx in the second stage was characterised by the burning of soap. It is also evident that the burning rate of soap was much higher than that of glycerol.

\subsection{Occurrence of Sodium Ions in the Flame of Soap-Doped Glycerol Droplets.}

Figure 6 shows the emission spectra of the flames of glycerol droplets with soap additions. The spectra showed all possible light emissions ranging from $400 \mathrm{~nm}$ to $750 \mathrm{~nm}$ during the combustion process and a clear spectrum with major feature near $689 \mathrm{~nm}$ corresponding to the atomic emission lines of sodium (Makino \& Fukada, 2005). The sodium signal from the flames of soap-doped glycerol droplets and the intensity of sodium signal increased with increasing soap concentration, displaying that a droplet with a higher soap concentration released more sodium in the flame. The finding is consistent with the combustion phenomenon observed and discussed in Section 3.1.

Based on the evidence presented above, the mechanism of the soap in promoting glycerol combustion has been proposed as follows. It has been found that soap started to decompose at ca.500K, which is lower than the boiling temperature of the glycerol (563K) (Folarin et al., 2011). This means the soap would decompose during the burning of the glycerol. When the surface temperature increases to the decomposition temperature of soap, the soap decomposes, releasing sodium atoms in the reaction zone, which promotes the oxidation of the fuel vapour. This results in 
a higher reaction rate and increases the flame temperature of the droplet. Consequently, the heat transfer to the droplet is enhanced by the higher flame temperature, leading to a higher burning rate and shorter burnout time. This is consistent with the literature report that atomic sodium promotes ignition and combustion of hydrocarbons (Graham, et al., 1976).

\section{Conclusions}

An experimental study on the effect of soap addition on the ignition and combustion characteristics of glycerol droplets at air temperature $1023 \mathrm{~K}$ has been carried out. The ignition delay time, burnout time, and burning rate of single droplets of glycerol with and without addition of soap have been systematically determined, along with the sodium intensity in the flame. It was found that the ignition and combustion process of soap-doped glycerol droplets occurred in a two-staged manner: in the first stage, glycerol preferentially was evaporated and combusted and in the second stage the soap was evaporated and burned. This resembled evaporation behaviour of binary mixtures with vastly different volatilities. The addition of soap in glycerol slightly reduced the ignition delay time and shortened burnout time of the droplets. The burning rate of glycerol became greater with increasing soap content. The presence of sodium ions in the flames of the soap in glycerol droplets was detected, which promoted the ignition and subsequent combustion of the fuel vapours.

\section{Acknowledgement}

Financial supports have been received from the Australian Research Council under the ARC Discovery Project scheme (DP110103699) and ARC Linkage Project scheme (LP100200135). Financial and other supports have also been received from BHP Billiton Iron Ore Pty Ltd and Ansac Pty Ltd. Hendrix Setyawan also acknowledges the Australian Commonwealth Government for providing the Australia Awards Scholarship (AAS). 


\section{References}

1. Bohon, M. D., Metzger, B. A., Linak, W. P., King, C. J. and Roberts, W. L. 2011. Glycerol combustion and emissions. Proc. Combust. Inst., 33, 2717-2724.

2. Botero, M. L., Huang, Y., Zhu, D. L., Molina, A. and Law, C. K. 2012. Synergistic combustion of droplets of ethanol, diesel and biodiesel mixtures. Fuel, 94, 342-347.

3. Cammenga, H. K., Schulze, F. W. and Theuerl, W. 1977. Vapor pressure and evaporation coefficient of glycerol. J. Chem. Eng. Data, 22, 131-134.

4. Canny, J. 1986. A computational approach to edge detection. IEEE Trans Pattern Anal Mach Intell, 8, 679-98.

5. Cheong Y. S., 1998. The Role of Aluminum-Surface Alloying in Improving the Corrosion Resistance of Silicon Nitride under the Influence of Sodium Vapor, PhD thesis, Stevens Institute of Technology, Hoboken, New Jersey

6. Ciriminna, R., Della-Pina, C., Rossi, M. and Pagliaro, M. 2014. Understanding the glycerol market. Eur. J. Lipid Sci. Technol., 116, 8.

7. Coronado, C. R., Carvalho JR, J. A., Quispe, C. A. and Sotomonte, C. R. 2014. Ecological efficiency in glycerol combustion. Appl. Therm. Eng., 63, 97-104.

8. Da Silva, C. X. A. and Mota, C. J. A. 2011. The influence of impurities on the acidcatalyzed reaction of glycerol with acetone. Biomass Bioenergy, 35, 3547-3551.

9. Da Silva, G. P., Mack, M. and Contiero, J. 2009. Glycerol: A promising and abundant carbon source for industrial microbiology. Biotechnol. Adv., 27, 30-39.

10. Dee, V. and Shaw, B. D. 2004. Combustion of propanol-glycerol mixture droplets in reduced gravity. Int. J. Heat Mass Transfer, 47, 4857-4867.

11. Ferguson, R. H. and Vold, R. D. 1938. The vapor pressure of commercial soaps. Oil \& Soap, 15, 181-183. 
12. Folarin O.M., Eromosele I.C., Eromosele C.O. 2011. Relative thermal stability of metal soaps of Ximenia Americana and Balanites aegyptiaca seed oils, Sci. Research Essays 6 (9) 1922-1927.

13. Graham, J. P., Ryer, J. and Lestz, S. J. 1976. Gasoline Composition Containing a Sodium Additive, US Patents No US 3955938 A.

14. Hu, S., Luo, X., Wan, C. and Li, Y. 2012. Characterization of Crude Glycerol from Biodiesel Plants. J. Agric. Food. Chem., 60, 5915-5921.

15. Law, C. K. 2006. Combustion Physics, New York, United States of America, Cambridge University Press.

16. Lissianski, V. V., Zamansky, V. M. and Maly, P. M. 2001. Effect of metal-containing additives on nox reduction in combustion and reburning. Combust. Flame, 125, 1118-1127.

17. Makino, A. and Fukada, H. 2005. Combustion behavior of a falling sodium droplet: Burning rate-constant and drag coefficient. Heat Transfer-Asian Research, 34, 481-495.

18. McNeil, J., Day, P. and Sirovski, F. 2012. Glycerine from biodiesel: The perfect diesel fuel. Process Saf. Environ. Prot., 90, 180-188.

19. Papanikolaou, S., Fakas, S., Fick, M., Chevalot, I., Galiotou-Panayotou, M., Komaitis, M., Marc, I. and Aggelis, G. 2008. Biotechnological valorisation of raw glycerol discharged after bio-diesel (fatty acid methyl esters) manufacturing process: Production of 1, 3propanediol, citric acid and single cell oil. Biomass Bioenergy, 32, 60 - 71.

20. Patzer, R., M. Norris, A. Doering, Jorgenson, R., C. Neece and Zimmerli, B. 2007. Stack Emissions Evaluation: Combustion of Crude Glycerin and Yellow Grease in an Industrial Fire Tube $\quad$ Boiler. Available: http://www.auri.org/wpcontent/assets/legacy/research/Glycerin\%20Report\%20Final.pdf. (accessed December 2015) 
21. Quispe, C. A. G., Coronado, C. J. R. and Carvalho JR, J. A. 2013. Glycerol: Production, consumption, prices, characterization and new trends in combustion. Renewable and Sustainable Energy Reviews, 27, 475-493.

22. Raslavičius, L. 2012. Characterization of the woody cutting waste briquettes containing absorbed glycerol. Biomass Bioenergy, 45, 144-151.

23. Setyawan, H. Y., Zhu, M., Zhou, W. and Zhang, D. 2013. Effect of Methanol Addition on Combustion Characteristics of Single Droplets of Glycerol. Proc. Aust. Combust. Symp. Nov 6th to 8th, 2013, The University of Western Australia, 332-335.

24. Setyawan, H. Y., Zhu, M., Zhang, Z. and Zhang, D. 2015. An Experimental Study of Effect of Water on Ignition and Combustion Characteristics of Single Droplets of Glycerol. Energy Procedia, 75, 578-583.

25. Shah, N. R. and Zakhor, A. 1999. Resolution enhancement of color video sequences. Image Processing, IEEE Transactions, 8, 879-885.

26. Steinmetz, S. A., Herrington, J. S., Winterrowd, C. K., Roberts, W. L., Wendt, J. O. L. and Linak, W. P. 2013. Crude glycerol combustion: Particulate, acrolein, and other volatile organic emissions. Proc. Combust. Inst., 34, 2749-2757.

27. Striugas, N., Šlančiauskas, A., Makarevičiene, V., Gumbyte, M. and Janulis, P. 2008. Processing of the glycerol fraction from biodiesel production plants to provide new fuels for heat generation. Energetika, 5, 5-12.

28. Wongwuttanasatian, T., Sakkampang, C. 2016. Combustion characteristics and emission of briquette fuel from biomass mixed with glycerin. Combust. Sci. Technol., Available: http://dx.doi.org/10.1080/00102202.2015.1136298 (accessed: April 2016)

29. Zhu, M., Ma, Y. and Zhang, D. 2012. A theoretical investigation into the effect of a homogeneous catalyst on combustion characteristics of single droplets of diesel and biodiesel, Chemeca, Engineers Australia, New Zealand, 543-553. 
30. Zhu, M., Ma, Y. and Zhang, D. 2013. Effect of a homogeneous combustion catalyst on combustion characteristics of single droplets of diesel and biodiesel. Proc. Combust. Inst., $34,1537-1544$. 


\section{Figure Captions}

Figure 1 A schematic of experimentation apparatus of single droplet combustion equipped with; (a) CCD camera and (b) flame emission spectrometer

Figure 2 Typical time-sequenced images of burning glycerol droplets with and without soap additions at $1023 \mathrm{~K}$; Image $1(\mathrm{t}=0)$ indicates the moment when the droplets arrived at the centre of the furnace and Image 2 shows the moments of droplets ignition)

Figure 3 Normalised temporal evolution of the squared diameter $\left(d / d_{o}\right)^{2}$ for droplets of pure glycerol, $5 \mathrm{wt} \%$ soap in glycerol, and pure soap at $1023 \mathrm{~K}$

Figure 4 The ignition delay time, burnout time and total combustion time of glycerol droplets with soap addition at different concentrations at $1023 \mathrm{~K}$

Figure 5 The burning rates of glycerol droplets with the addition of different amounts of soap: (a) Stage 1 and (b) Stage 2

Figure 6 Signals of sodium in flames of droplets with various concentrations of soap in glycerol 
Figure 1
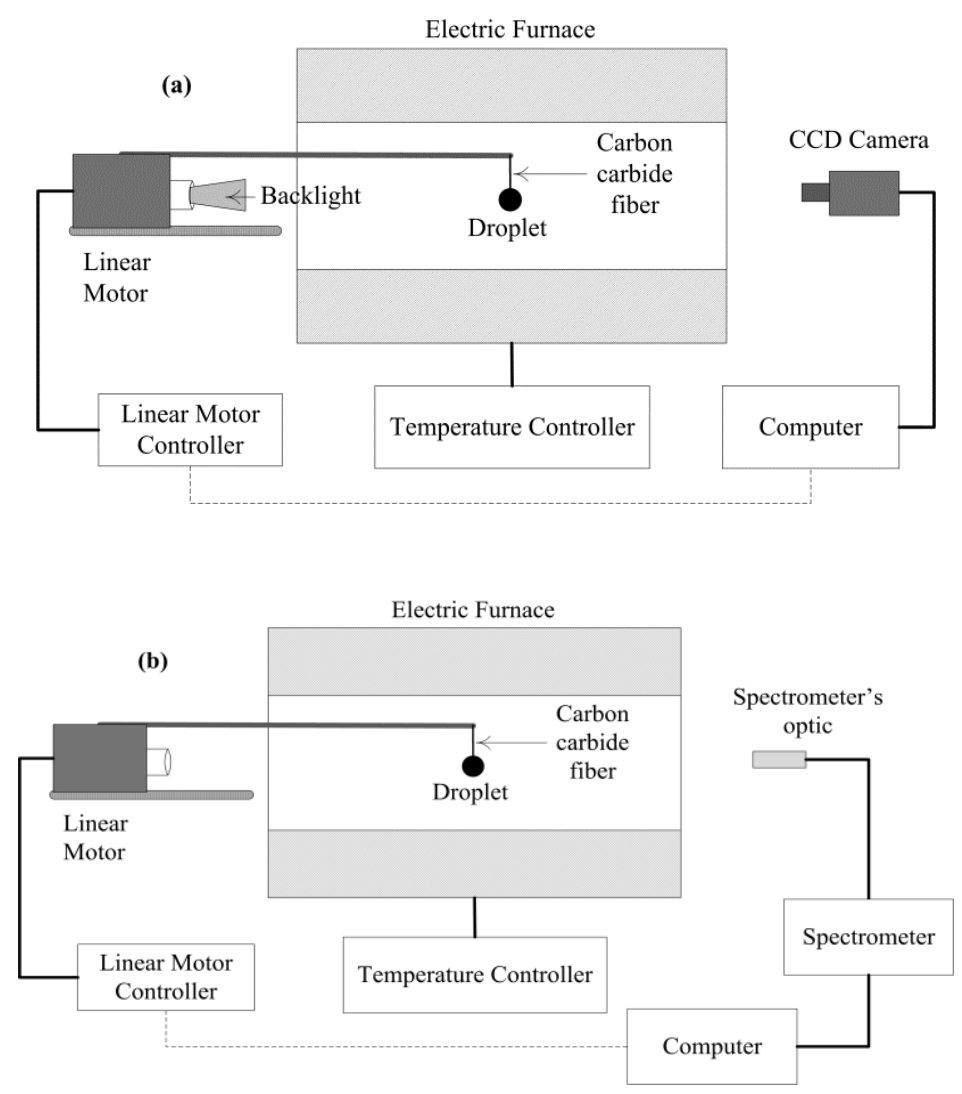

Figure 1 A schematic of experimentation apparatus of single droplet combustion equipped with;

(a) CCD camera and (b) flame emission spectrometer 
Figure 2

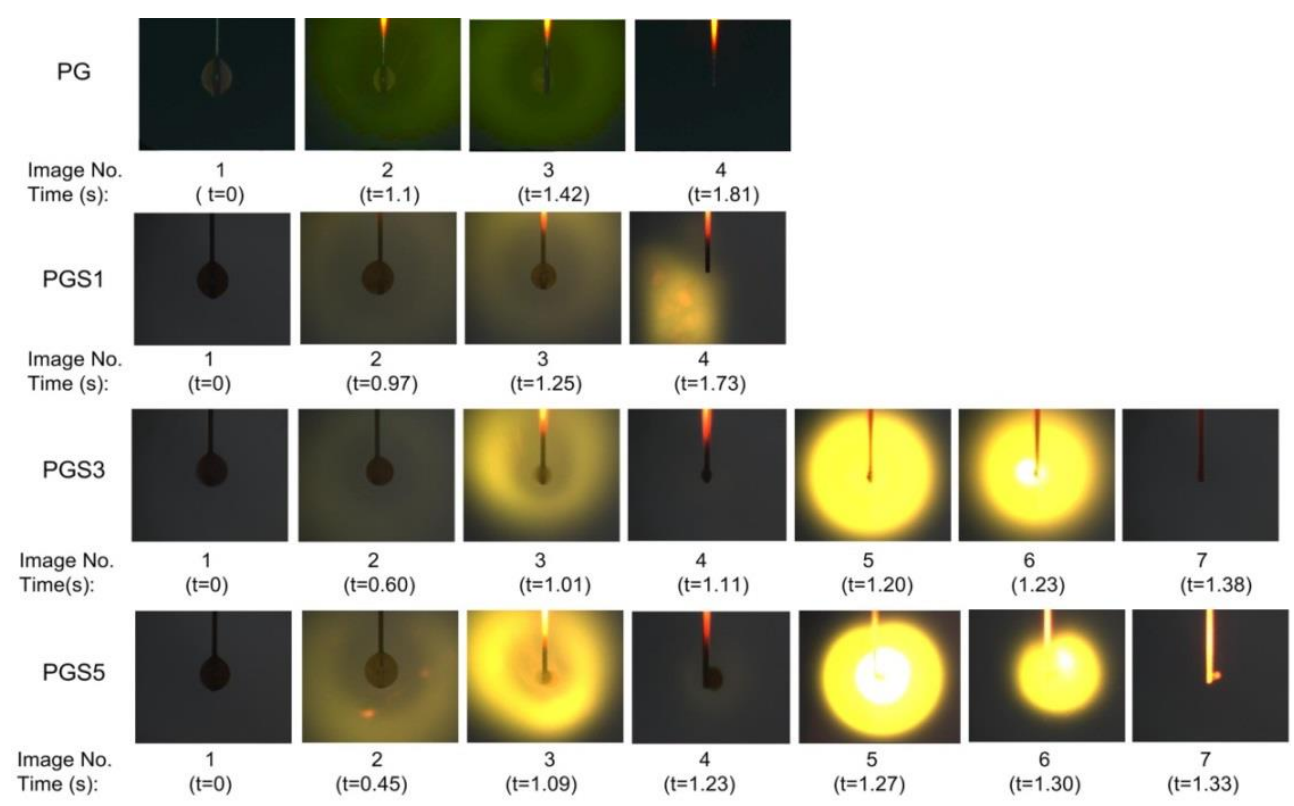

Figure 2 Typical time-sequenced images of burning glycerol droplets with and without soap additions at 1023K; Image $1(\mathrm{t}=0)$ indicates the moment when the droplets arrived at the centre of the furnace and Image 2 shows the moments of droplets ignition) 
Figure 3

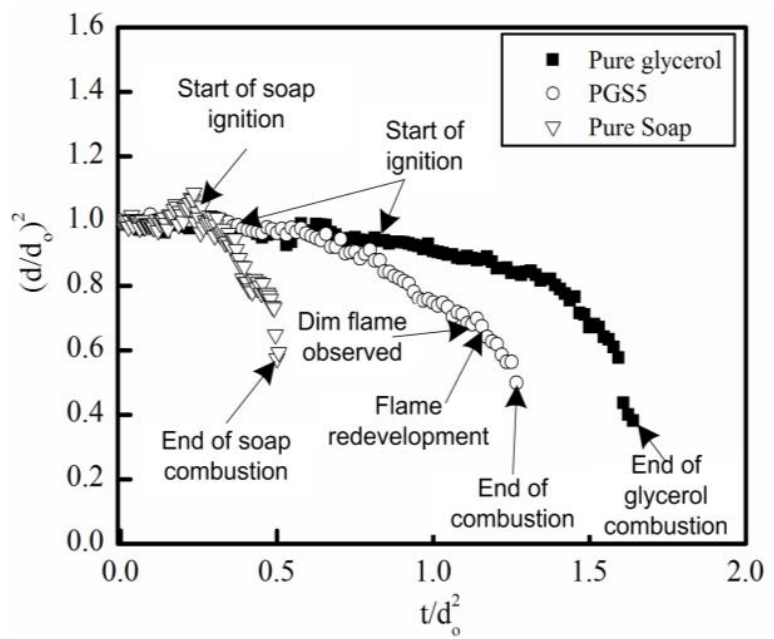

Figure 3 Normalised temporal evolution of the squared diameter $\left(d / d_{o}\right)^{2}$ for droplets of pure glycerol, 5 wt $\%$ soap in glycerol, and pure soap at $1023 \mathrm{~K}$ 
Figure 4

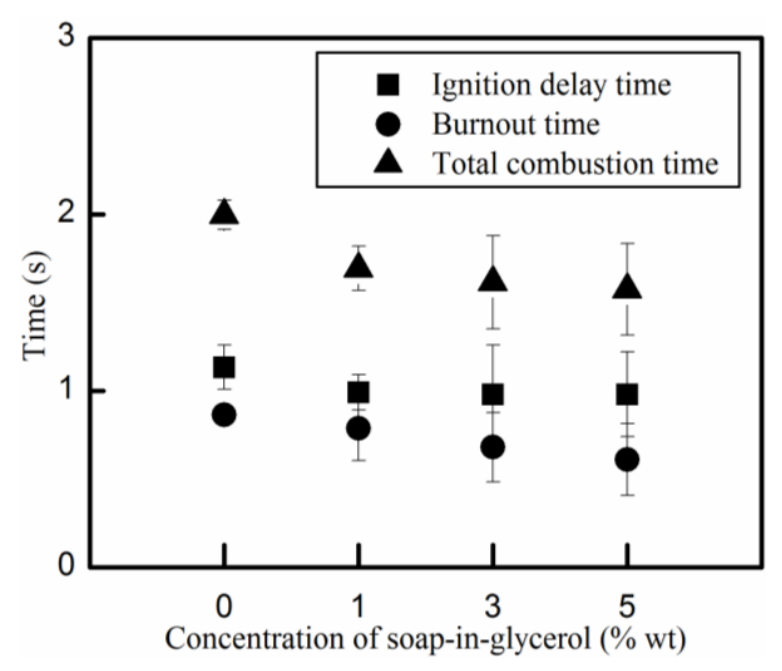

Figure 4 The ignition delay time, burnout time and total combustion time of glycerol droplets with soap addition at different concentrations at $1023 \mathrm{~K}$ 
Figure 5
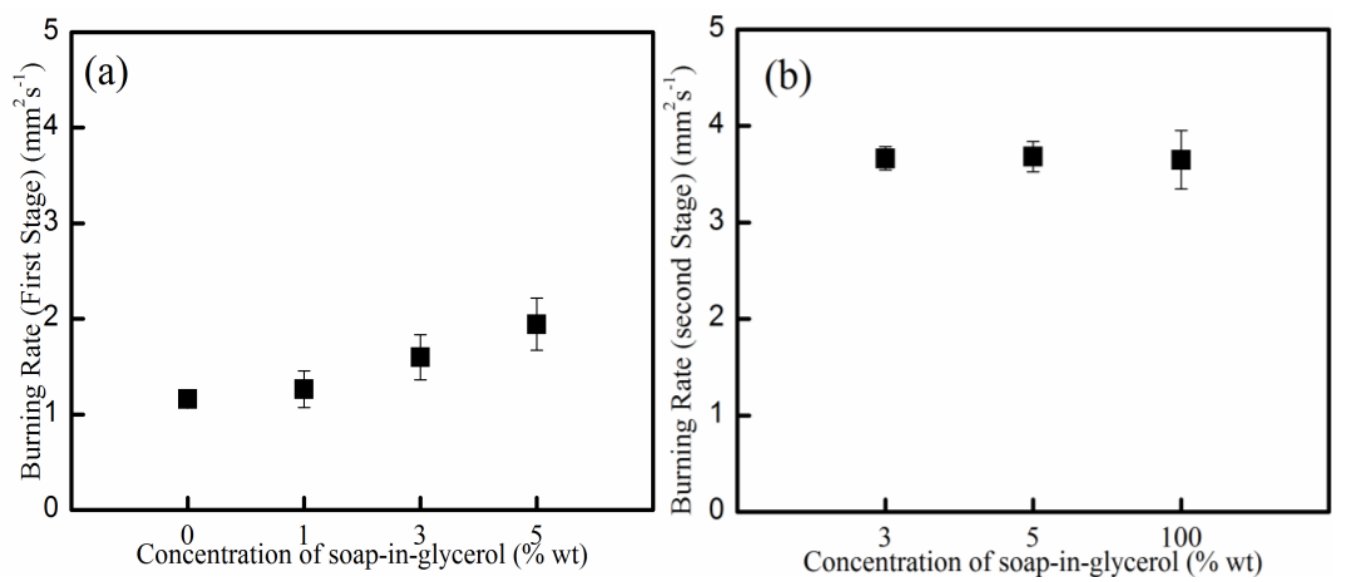

Figure 5 The burning rates of glycerol droplets with the addition of different amounts of soap: (a)

Stage 1 and (b) Stage 2 
Figure 6

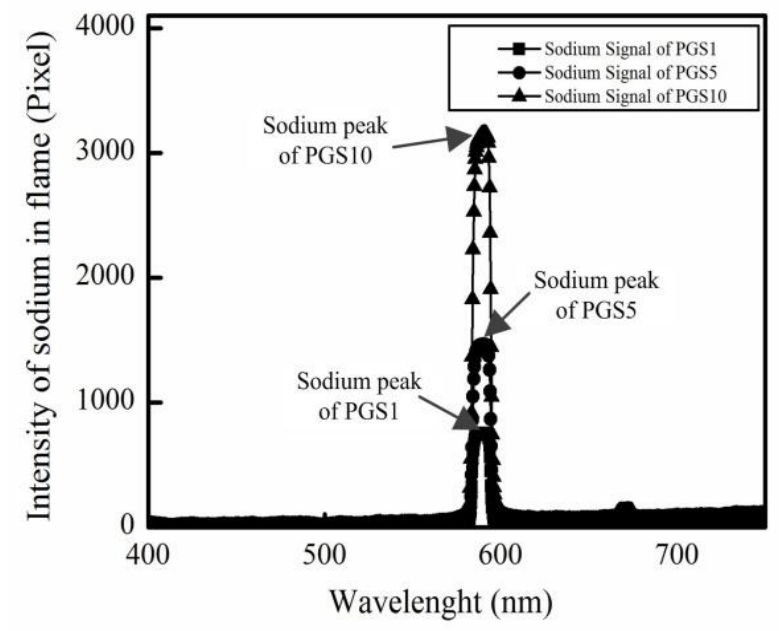

Figure 6 Signals of sodium in flames of droplets with various concentrations of soap in glycerol 


\section{Table Captions}

Table 1 Key physical and thermodynamic properties of glycerol $[8,9]$

Table 2 The compositions of the olive oil used in the present study 
1 Table 1 Key physical and thermodynamic properties of glycerol [8, 9]

\begin{tabular}{lc}
\hline \multicolumn{1}{c}{ Fuel property } & Glycerol \\
\hline Formula & $\mathrm{C}_{3} \mathrm{H}_{8} \mathrm{O}_{3}$ \\
Density $\left(\mathrm{kgm}^{-3}\right)$ & 1261 \\
Heating value $\left(\mathrm{MJkg}^{-1}\right)$ & 18 \\
Boiling point (K) & 563 \\
Cetane number & 5 \\
Viscosity (mPa.s) & 1500 \\
Auto-ignition temperature $(\mathrm{K})$ & 796 \\
Flash point (K) & 450 \\
Specific heat capacity $\left(\mathrm{kJ} \mathrm{kg}^{-1}\right)$ & 2.43 \\
Thermal conductivity $\left(\mathrm{Wm}^{-1} \mathrm{~K}^{-1}\right)$ & 0.2900 \\
\hline
\end{tabular}

2

3 
4 Table 2 The compositions of the olive oil used in the present study

\begin{tabular}{llc}
\hline Fatty Acid in Olive oil & & Concentration (\%) \\
\hline Lauric acid & $\mathrm{C}_{12}$ saturated & 0 \\
Myristic acid & $\mathrm{C}_{14}$ saturated & 0 \\
Palmitic acid & $\mathrm{C}_{16}$ saturated & 11 \\
Stearic acid & $\mathrm{C}_{18}$ saturated & 2 \\
Oleic acid & $\mathrm{C}_{18}$ monounsaturated & 78 \\
Linoleic acid & $\mathrm{C}_{18}$ di-unsaturated & 10 \\
Linolenic acid & $\mathrm{C}_{18}$ tri-unsaturated & 0 \\
\hline
\end{tabular}

5

6

7 